
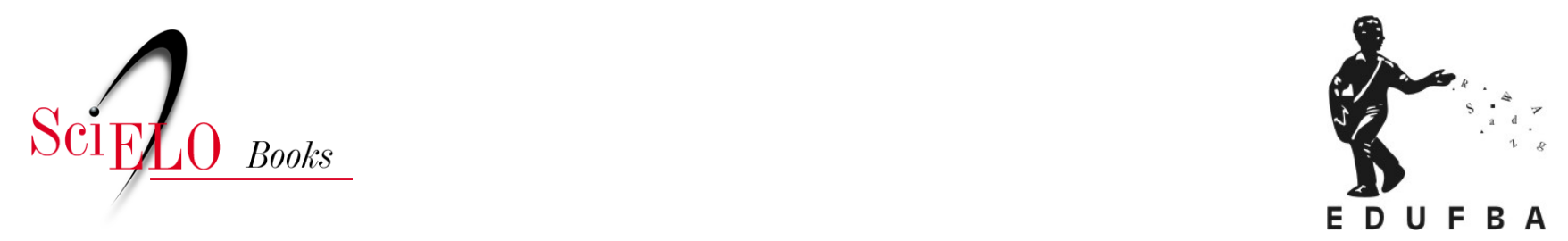

\title{
A vigilância sanitária e a qualidade na atenção hemoterápica
}

\author{
Helder Teixeira Melo \\ Giselle Bissaro Barban Evangelista
}

MELO, H.T., and EVANGELISTA, G.B.B. A vigilância sanitária e a qualidade na atenção hemoterápica. In: SOUZA, M.K.B., comp. Planejamento e gestão em saúde: caminhos para o fortalecimento das hemorredes [online]. Salvador: EDUFBA, 2018, pp. 89-104. ISBN 978-85-232-2027-3.

https://doi.org/10.7476/9788523220273.0006.

International license.

Todo o conteúdo deste trabalho, exceto quando houver ressalva, é publicado sob a licença Creative Commons Atribição 4.0. 


\title{
A vigilância sanitária e a qualidade na atenção hemoterápica
}

\author{
Helder Teixeira Melo \\ Giselle Bissaro Barban Evangelista
}

\section{Introdução}

Até o século XX as atividades relacionadas a hemoterapia tinham seu caráter empírico, fundamentadas na crença de que o sangue poderia salvar vidas. De fato, o senso comum sobre a questão, levava médicos e práticos a testar procedimentos transfusionais diversos, com finalidades terapêuticas hoje consideradas duvidosas ou até mesmo proibidas, como as transfusões heterólogas (entre espécies diferentes) e as transfusões braço a braço, que ocorriam em técnicas cirúrgicas que permitiam a transfusão direta, utilizando-se a artéria do doador e a veia do receptor por meio de aparelhos especialmente desenvolvidos para este fim. (FUNDAÇÃO PRÓ-SANGUE, [200-])

Nessa questão, Junqueira, Rosenblit e Hamerschlak (2005) dividem a transfusão de sangue, no mundo, em dois períodos distintos: um empírico, que vai até 1900; e, outro científico, de 1900 em diante.

A principal revolução científica, a qual deu início à hemoterapia como especialidade terapêutica, foi a descoberta do Dr. Karl Landsteiner sobre efeitos aglutinantes e grupos sanguíneos no início do século XX. (MELO, 2015) A partir de então, tornou-se possível a realização de provas de compatibilidade 
imunohematológica, resolvendo diversos problemas relacionados a reações transfusionais graves.

Ainda nos primórdios da hemoterapia, a descoberta das soluções anticoagulantes e conservantes, como o difosfato de sódio, e o aperfeiçoamento e desenvolvimento de equipamentos para coleta e armazenamento do sangue, bem como de refrigeração, permitiu a organização dos centros de armazenamento que possibilitavam a formação de estoques de sangue para posterior uso. Já na década de 1930, em todo o mundo e inclusive no Brasil, abriu-se espaço para a criação de estabelecimentos de "saúde", que passaram a ser conhecidos como "bancos de sangue".

Saraiva (2005) ressalta que apesar do pioneirismo da hemoterapia brasileira, a regulamentação estatal não acompanhava o desenvolvimento da especialidade. Melo (2015) reforça que a ausência do poder público e o atraso da regulamentação do setor foram prejudiciais ao desenvolvimento da hemoterapia, tendo como consequência, o estímulo à proliferação de bancos de sangue privados e a comercialização dos produtos hemoterápicos, gerando impactos no processos da doação de sangue. (SARAIVA, 2005)

Somente a partir da promulgação da Lei n ${ }^{\circ} 4.701$, de 28 de junho de 1965, o controle sanitário passou a existir, sendo criado o primeiro ordenamento púlico da área de sangue, com: um órgão normativo e consultivo, ocupando-se do disciplinamento da referida atividade em todo o território nacional; os órgãos de fiscalização, com autoridade de âmbito nacional, estadual, territorial e municipal, atuando no campo da saúde pública; e, órgãos executivos da prática hemoterápica.

Porém, até a década de 1980, não era possível identificar a estruturação de um sistema de serviços de hemoterapia que promovesse a qualificação da produção hemoterápica, em nível nacional, fosse pela padronização de procedimentos técnicos, ou fosse pela aplicação de uma política que garantisse a autossuficiência do país em produtos hemoterápicos para a assistência à saúde.

Outros problemas de ordem técnica relativa à segurança transfusional persistiam, como a remuneração de doadores de sangue e a existência de doadores de substituição, com taxas de até $80 \%$, o que provocava entre $40 \%$ a 70\% de inaptidão nas triagens clínica e laboratorial, e menos 10\% de doadores de repetição nos hemocentros. (HOGAN; GARGARELLA, 1997) 
Ainda mais grave à segurança dos produtos e serviços prestados pela hemoterapia, foi o impacto da eclosão da pandemia mundial do vírus da Imunodeficiência Adquirida (HIV) e da Síndrome da Imunodeficiência Adquirida (AIDS) em meados da década de 1980. Apesar de haver outros patógenos causadores de doenças transmissíveis por transfusão à época, como o vírus da Hepatite B e outros, a comoção social relacionada, tanto ao estigma trazido com a AIDS, quanto a preocupação sanitária tardia, reforçaram radicalmente o controle sorológico dos produtos hemoterápicos.

Além de um extensa regulamentação técnica no setor, a Lei no ${ }^{\circ} .649 / 1988$, estabeleceu "[...] a obrigatoriedade do cadastramento dos doadores de sangue, bem como a realização de exames laboratoriais no sangue coletado, com objetivo de prevenir a propagação de doenças [...]”. (BRASIL, 1988b)

Em seguida, no mesmo ano a Constituição do Brasil, trouxe em seu texto a proibição da comercialização do sangue. Com a proibição da remuneração do doador o país passou a contar exclusivamente com a doação voluntária não remunerada de sangue para o abastecimento dos serviços. (MELO, 2015)

Foi a partir de 1990 que a Saúde Pública no Brasil teve impulso com a promulgação do marco legal do Sistema Único de Saúde (SUS), Lei nº 8.080/1990, que incluiu como prioridades a formulação e execução de uma nova política de sangue para o país, a implementação do Sistema Nacional de Sangue, bem como a implementação de ações de vigilância sanitária no âmbito destas políticas. (BRASIL, 1990)

No contexto, marcado pela regulamentação do SUS, foi proposto um projeto de lei da Câmara dos Deputados iniciado em 1991, para definir os órgãos operacionais das atividades hemoterápicas e da produção de hemoderivados e estabelecer a estrutura de gestão do Sistema Nacional de Sangue, Componentes e Derivados. (MELO, 2015) Projeto o qual, somente foi promulgado dez anos mais tarde, pela Lei $n^{\circ} 10.205$, de 21 de março de 2001 (Lei do Sangue).

Em todo este desenvolvimento da área de sangue a preocupação com a regulação e vigilância sanitária mostrou-se presente por meio do controle e fiscalização de serviços de hemoterapia, produtos e procedimentos utilizados na atenção hemoterápica, com vistas à redução de riscos à saúde. 


\section{A importância da vigilância sanitária do sangue como instrumento de gestão na saúde}

Costa e Rozenfeld (2000) comentam que a Vigilância Sanitária é a forma mais complexa de existência da saúde pública, pois suas ações, de natureza eminentemente preventiva, perpassam todas as práticas médico-sanitárias: promoção, proteção, recuperação e reabilitação da saúde.

A constituição da Vigilância Sanitária é tão antiga quanto à formulação de estratégias políticas de saúde pública, em especial para a prevenção da transmissão de doenças e controle de epidemias. No Brasil, a organização da Vigilância Sanitária remonta ao período da Monarquia, em especial com a chegada da família real portuguesa, em 1808, e a estruturação do Reino Unido de Portugal, Brasil e Algarves, em 1815. À época, o controle sanitário de produtos de importação e da produção de bens e serviços, ganhou importância na prevenção de doenças e epidemias, em especial nos grandes centros.

A evolução da Vigilância Sanitária no país acompanhou o desenvolvimento do próprio tema da saúde, fiscalizando não apenas os bens e produtos circulantes de interesse à saúde coletiva, como também os serviços de saúde utilizados na prestação da assistência às pessoas.

A Lei ${ }^{\circ}$ 8.080, de 19 de setembro de 1990, definiu a Vigilância Sanitária no âmbito do SUS como "[...] um conjunto de ações capaz de eliminar, diminuir, ou prevenir riscos à saúde e de intervir nos problemas sanitários decorrentes do meio ambiente, da produção e circulação de bens e da prestação de serviços de interesse da saúde [...]”. (BRASIL, 1990)

Para a execução destas ações foi criado o Sistema Nacional de Vigilância Sanitária (SNVS), composto por instituições da Administração Pública das três esferas de governo, com atividades de regulação, normatização, controle e fiscalização de produtos, substâncias e serviços de interesse para a saúde. A Lei ${ }^{\circ}$ 9.782, de 26 de janeiro de 1999, estabeleceu ainda, a Política Nacional de Vigilância Sanitária, sob a direção da Agência Nacional de Vigilância Sanitária (Anvisa). (BRASIL, 1999)

A Lei n ${ }^{\circ}$ 9.782/99 criou a Agência Nacional de Vigilância Sanitária (Anvisa) que atualmente é composta pelo Instituto Nacional de Controle de Qualidade em Saúde (INCQS), vinculado à Fundação Oswaldo Cruz (Fiocruz) e 27 órgãos estaduais de vigilância sanitária e também os órgãos municipais. Assim, 
a organização do sistema regulatório é executada por órgãos que, coordenados pela Anvisa, compõem o Sistema Nacional de Vigilância Sanitária (SNVS). (SILVA JÚNIOR; COSTA; BACCARA, 2015)

Apenas para fins de contextualização, é salutar compreender o que envolve as atividades de vigilância sanitária descritas na lei, a fim de evidenciar os impactos da Vigilância Sanitária sobre o campo de atividades da hemoterapia:

- Regulação: compreendida como o modo de intervenção do Estado para impedir possíveis danos ou riscos à saúde da população. A atuação da Vigilância Sanitária se dá por meio da regulamentação, controle e fiscalização das relações de produção; e consumo de bens e serviços relacionados à saúde, bem como registros e autorizações sanitárias para todos os insumos e materiais comercializados referentes ao processamento do sangue;

- Normatização: que consiste na publicação de normas regulatórias estabelecidas pelo Ministério da Saúde com o propósito de padronizar os procedimentos técnicos a serem seguidos por todos os serviços de hemoterapia;

- Controle: que visa garantir a utilização correta de produtos e serviços adequados e com base nos requisitos de boas práticas aplicadas ao ciclo do sangue;

- Fiscalização: executada por meio da inspeção sanitária realizada pelos órgãos reguladores locais, com o objetivo de auditar o cumprimento das normas regulatórias nacionais pela aplicação de roteiros de inspeção e instrumentos de avaliação de risco inerentes ao ciclo do sangue. (SILVA JÚNIOR; COSTA; BACCARA, 2015)

Costa (2009) comenta que em todas as épocas ocorreram intervenções do Poder de Autoridade sobre as práticas de cura, os medicamentos, os alimentos, a água, o ambiente. Com o avanço das forças produtivas, surgiram intervenções sobre a circulação dos meios de transporte, cargas e pessoas, bem como sobre o consumo da força de trabalho, mediante distintas formas de regulação e intervenção nas práticas do mercado. 
Atualmente, a Vigilância Sanitária optou por assumir um caráter mais educativo na promoção da saúde, em especial no que se refere às ações de inspeção para fiscalização na área de sangue. Este caráter educativo, mesmo que positivo sobre as ações de Vigilância Sanitária (VISA) e inovador no processo de saúde, não pode ser compreendido como um relaxamento do Poder de Autoridade (poder de polícia), atribuído às instituições do setor.

Obviamente, o exercício do Poder de Autoridade Sanitária está limitado à questão técnica que envolve o conjunto de ações da VISA e suas consequências políticas e jurídicas. Porém, suas ações visam garantir a redução de riscos relativos à atividade hemoterápica para a população.

Ainda que seja do senso comum que a garantia do acesso da população aos produtos e serviços hemoterápicos seja de competência dos organismos operacionais, isto é, serviços de hemoterapia da Hemorrede Nacional, fato inclusive assegurado no ordenamento jurídico da Hemoterapia, em especial no Decreto $\mathrm{n}^{\circ} 3.990 / 2001$, a garantia de que este acesso se dará de forma efetiva e segura é função partilhada com os órgãos de Vigilância Sanitária; isso, seja no uso de insumos e equipamentos previamente submetidos a registro pela autoridade sanitária, seja na controle e fiscalização de procedimentos e ambientes dos estabelecimentos técnicos, ou mesmo no acompanhamento dos avanços científicos, tecnológicos e inovações no setor.

A importância das ações da Vigilância Sanitária, no acesso a produtos seguros e efetivos na área de sangue, é ressaltada pela Organização Mundial da Saúde (2014) que sugere aos países membros que seus respectivos Ministérios da Saúde tenham uma liderança eficaz e governança no desenvolvimento de um sistema nacional de sangue totalmente integrado ao sistema de saúde, de forma a prover de maneira responsável a segurança transfusional e a disponibilidade de sangue e derivados. Para tanto, além das regulamentações técnicas pertinentes e de um quadro legislativo e regulamentar para o programa nacional de sangue, a promoção da saúde deve ser "regulamentada, fiscalizada e controlada pelo poder público". (DIAS, 2002, p. 17)

Para se alcançar segurança dos produtos sanguíneos a serem utilizados em transfusões, rígidos parâmetros de qualidade devem ser perseguidos. Entende-se por segurança transfusional o conjunto de medidas quantitativas e qualitativas adotadas que vise um menor risco aos doadores e receptores 
de sangue, além da garantia de estoques estratégicos de sangue capazes de atender à demanda transfusional. (O'DWYER; REIS; SILVA, 2010)

Embora haja significativos avanços na busca de segurança transfusional, não existe transfusão isenta de riscos (PIMENTEL, 2006; MURPHY, 2006; SANTOS; MORAES; COELHO, 1992), nesse sentido é de suma importância o cumprimento do disposto nas normas e regulamentos técnicos referentes ao ciclo do sangue, para garantir que os riscos inerentes a todo o processo, que se inicia na captação e seleção de doadores, triagem sorológica, imunohematológica e molecular referente ao teste de ácidos nucléicos, obrigatórios no Brasil a partir de 2012, processamento e fracionamento das unidades coletadas, dispensação, transfusão e avaliação pós transfusional, sejam previstos e evitados. Assim, é claramente percebida a presença das ações de Vigilância Sanitária no planejamento da Política de Sangue para atenção hemoterápica da população, visando sua proteção. (MURPHY; STANWORTH; YAZER, 2011)

\section{A importância da autoridade e regulação sanitária no planejamento das ações na área de sangue}

O papel da vigilância sanitária da área de sangue foi ressaltado em 1999, quando no processo de criação da Anvisa, foi transferido para o referido órgão a condução da Política Nacional de Sangue. O protagonismo da agência reguladora não se deu apenas no âmbito de sua função precípua de regulação, controle e fiscalização, mas também da direção da Política Nacional de Sangue, Componentes e Derivados a partir da promulgação da Lei nº 10.205/2001, reforçado pelo decreto de regulamentação, Decreto $n^{\circ} 3.990 / 2001$ (texto original) até o ano de 2004.

Nesse período verifica-se uma intensa atividade normativa, com a revisão de diversos regulamentos técnicos referentes à execução de procedimentos hemoterápicos, regramentos para utilização de componentes e derivados sanguíneos, regulamentos quanto ao uso e produção de hemoderivados e orientações sobre a estrutura organizacional da Hemorrede, com a internalização de normas internacionais, que culminaram na Resolução RDC n 151 , de 22 de agosto de 2001, que aprovava o Regulamento Técnico sobre Níveis de Complexidade dos Serviços de Hemoterapia (artigo $1^{\circ}$ ) e que veio também estabelecer o padrão de nomenclatura atualmente adotado pela Hemorrede 
Nacional para esses serviços. (AGÊNCIA NACIONAL DE VIGILÂNCIA SANITÁRIA, 2001)

Desde a primeira formação do Decreto ${ }^{\circ}$ 3.990/2001, a importância da Vigilância Sanitária no apoio à formulação do "plano diretor de sangue, componentes e hemoderivados" dos estados e do Distrito Federal, recebe especial destaque, com vistas ao acompanhamento e a avaliação do cumprimento das metas e das ações do SINASAN. Os artigos $5^{\circ}$ e $6^{\circ}$ ressaltam a competência dos gestores estaduais do SUS que devem “[...] coordenar, em seus limites geográficos, as ações na área de sangue, componentes e hemoderivados, incluindo as ações de vigilância sanitária e as atividades voltadas para o atendimento de situações de emergência [...]", além de fazer cumprir as “[...] normas técnicas pelos órgãos executores das ações de hemoterapia, por meio das ações de vigilância sanitária". (BRASIL, 2001a)

Outro destaque à importância da regulação sanitária no planejamento da hemoterapia decorre do Artigo $7^{\circ}$ do referido Decreto $n^{\circ} 3.990 / 2001$, que ao determinar aos gestores do SUS a implantação da estrutura dos sistemas de sangue, "câmaras de assessoramento para formulação da política de sangue, componentes e hemoderivados", explicita em seu parágrafo único que na constituição de tais "câmaras de assessoramento", minimamente devem fazer parte os representantes da "Vigilância Sanitária”, além da própria Hemorrede pública, vigilância epidemiológica, planejamento e controle e avaliação das secretarias estaduais de Saúde. (BRASIL, 2001a)

A formulação de planos nacionais quadrienais para o setor não tem logrado êxito na aprovação e/ou publicação normativa de tais documentos. Ao longo dos anos, percebe-se certa precarização no funcionamento das câmaras de assessoramento da Política de Sangue em alguns entes federativos nas diversas esferas de gestão do SUS, o que pode estar levando a prejuízos na formulação ou mesmo na aplicação destes planos. Esta questão, porém, deve ser tratada pelos gestores do SUS como prioritária, não apenas para o cumprimento do dispositivo regulamentado no Decreto $n^{\circ} 3.990 / 2001$, mas em especial, pela importância do estabelecimento de uma direção político-administrativa efetiva e exitosa para o desenvolvimento da hemoterapia nos estados.

Nesse aspecto o papel da Vigilância Sanitária é mais uma vez relevante, desde a identificação de situações problemáticas na oferta de serviços à população, quando é possível avaliar a precarização da assistência pela incor- 
reção e/ou inadequação de procedimentos em relação às normas técnicas e boas práticas, até a adoção de medidas efetivas para a redução de riscos e agravos à saúde da população.

A segurança transfusional, atualmente, é uma das principais preocupações da sociedade e dos gestores de serviços de saúde. Nos anos 1980, o advento da AIDS trouxe a preocupação com a transmissão transfusional de doenças e consequente aumento nas ações de fiscalização nos serviços, nas ações judiciais e na pressão da mídia evidenciando a situação da hemoterapia daquele período. Saraiva (2005), comenta que em meio ao "radicalismo", equívocos e turbulências da questão da AIDS, esta não era considerada prioritária por alguns representantes do Ministério da Saúde até 1985. "Somente dois anos após, o Ministério da Saúde tornou obrigatória a realização do teste sorológico para a detecção do anticorpo anti-HIV" em bancos de sangue. (SARAIVA, 2005, p. 157)

A preocupação com a transmissão transfusional do HIV foi expressa por meio de ato legislativo na Lei $n^{\circ} 7.649 / 1988$, o qual estabeleceu a obrigatoriedade do cadastramento dos doadores de sangue, bem como a realização de exames laboratoriais no sangue coletado, visando prevenir a propagação de doenças. (MELO, 2015) O descumprimento desta lei implica, inclusive, em sanções criminais aos responsáveis técnicos pelos serviços de hemoterapia.

Foi a partir desse período que houve a busca pelo aperfeiçoamento tecnológico dos conjuntos diagnósticos com o objetivo de torná-los mais sensíveis para detecção precoce dos marcadores infecciosos nas amostras de candidatos à doação de sangue, contribuindo assim com o desenvolvimento de uma das áreas de suma importância nos serviços de hemoterapia, a triagem laboratorial. Ainda, no controle da transmissão de doenças e agravos à saúde, destacam-se as ações de captação e do aprimoramento dos critérios de triagem clínica dos candidatos à doação sob a perspectiva do risco epidemiológico que permitem a seleção de doadores. (DOOD; NOTARI; STRAMER, 2002; BARBAN, 2015)

Importante lembrar que o protagonismo das ações de Vigilância Sanitária na redução de riscos na área de sangue não é limitado à fiscalização das estruturas físicas dos serviços, ou aos riscos de transmissão de patógenos infecciosos por transfusão. Em seu sítio virtual na internet, a Anvisa comenta que 
O uso de sangue, outros tecidos, células e órgãos humanos para tratamento de agravos é uma tecnologia já disponível no Brasil. Para garantir a qualidade e a segurança destes tratamentos, a vigilância sanitária elabora normas e regulamentos técnicos, inspeciona os serviços credenciados, capacita profissionais e monitora a ocorrência de eventos adversos com a utilização das tecnologias disponíveis. (AGÊNCIA NACIONAL DE VIGILÂNCIA SANITÁRIA, [200-])

Na Anvisa, essas atividades são desempenhadas pela área de Sangue, outros Tecidos, Células e Órgãos.

Um importante avanço no campo da segurança da transmissão de agentes infeciosos por transfusão e no controle dos processos laboratoriais, conforme destacado por Sampaio (2013, p. 15) são

[...] os Programas de Avaliação Externa da Qualidade em Serviços de Hemoterapia (AEQ), em sorologia e imuno-hematologia, que foram implantados e coordenados pela Agência Nacional de Vigilância Sanitária (Anvisa), no período de 2001 a 2009 e a partir de 2010 estão sob responsabilidade da CGSH do Ministério da Saúde.

A amplitude das ações de vigilância sanitária está presente desde o processo de registros de equipamentos e insumos para a atividade hemoterápica e fiscalização de sua produção, no funcionamento dos serviços, na responsabilidade técnica, no controle do armazenamento e transporte de insumos hemoterápicos, até a vigilância pós-uso dos produtos e equipamentos e a hemovilângia.

Além disso, o acesso da Autoridade Sanitária aos serviços de saúde torna este ente, o elo mais próximo da atuação de forma direta e imediata no controle e na solução de problemas locais que impactem negativamente na qualidade e segurança da assistência à saúde. No entanto, ainda há deficiência nesse acesso, como, por exemplo, a ausência do controle sanitário na assistência hematológica, uma vez que os serviços assistenciais da Hemorrede, de forma geral não têm sido objeto de verificação das equipes de fiscalização sanitária da área de sangue, a qual tem enfoque na produção hemoterápica e 
por vezes as áreas de serviços de saúde das Vigilâncias Sanitárias não evidenciam que parte da assistência hematológica pública encontra-se concentrada nos serviços de hemoterapia.

\section{Qualificação e aplicação de regras sanitárias nos Serviços de Hemoterapia}

Além do papel normativo de Regulação Sanitária e outras funções já referidas, a colaboração da Vigilância Sanitária também avança tanto no apoio à organização dos Serviços de Hematologia e Hemoterapia quanto no planejamento de ações da Hemorrede.

O controle de áreas e atividades críticas dos Serviços de Hemoterapia é atividade fundamental para garantir a efetividade das ações de saúde executadas pelos serviços e a segurança sanitária no uso dos ambientes, equipamentos e insumos utilizados nos processos de produção do sangue e componentes.

Para exercer a função de fiscalização e controle, importantes ferramentas merecem destaque, como os regulamentos técnicos de boas práticas, transporte de hemocomponentes, orientações para armazenamento de hemocomponentes, roteiros de inspeção e as ações de caráter eminente técnico, sendo capazes de reorientar procedimentos técnicos, promover ações preventivas e corretivas de riscos e agravos - hemovigilância, tecnovigilância e farmacovigilância.

A importância da fiscalização sanitária se dá em diversos campos tanto no ciclo do sangue, considerando a coleta, triagem, processamento, armazenamento e distribuição, como também, nas medidas de proteção ao doador e receptor; pela instituição de critérios de triagem que visam evitar efeitos adversos nos receptores; no gerenciamento de aquisição de insumos, na validação de processos; nos registros referentes às doações e transfusões; nas ações de hemovigilância; na gestão do risco; na proteção dos trabalhadores, não somente no ambiente de trabalho, mas com a identificação dos riscos de exposição e de ergonomia, que possam trazer problemas tardios aos profissionais dessas áreas; na gestão de resíduos de serviços de saúde; no transporte de amostras e hemocomponentes; nas atividades dos serviços de hemoterapia em relação ao meio ambiente. 
Em todas essas etapas do ciclo do sangue e de apoio a estes processos, a importância da regulação e fiscalização sanitária para que as ações sejam planejadas, implementadas e seguidas é primordial na garantia da segurança e qualidade transfusional.

Diversos regulamentos sanitários servem de orientação para tais ações e processos, tanto para as equipes de Vigilância Sanitária na área de sangue, quanto para a organização e planejamento dos serviços de hematologia e hemoterapia no âmbito da Hemorrede. Assim, entre os principais atos normativos sanitários encontrados na área de sangue, de interesse para o planejamento da Hemorrede e estruturação de serviços de hematologia e hemoterapia, destacam-se:

- Resolução RDC/ANVISA n ${ }^{\circ} 34$ de 11 de junho de 2014 - Dispõe sobre as Boas Práticas no Ciclo do Sangue;

- Resolução RDC/ANVISA n 36 de 25 de julho de 2013 - Institui ações para a segurança do paciente em serviços da saúde e dá outras providências;

- Resolução RDC/ANVISA n ${ }^{\circ}$ 306, de 7 de dezembro de 2004 - Dispõe sobre o Regulamento Técnico para o gerenciamento de resíduos de serviços de saúde;

- Resolução RDC/ANVISA n 50 de 21 de fevereiro de 2002 - Dispõe sobre o Regulamento Técnico para planejamento, programação, elaboração e avaliação de projetos físicos de estabelecimentos assistenciais de saúde;

- Resolução RDC $n^{\circ} 151$, de 21 de agosto de 2001 - Aprova o Regulamento Técnico sobre Níveis de Complexidade dos Serviços de Hemoterapia;

- Portaria Conjunta $\mathrm{n}^{\circ}$ 370, de 7 de maio de 2014 - Dispõe sobre o Regulamento Técnico-sanitário para o transporte de sangue e componentes.

Destas normas, é importante destacar a RDC/ANVISA n 34/2014. Resultante de uma evolução normativa da Agência Reguladora, esta resolução 
aplica o conceito de Boas Práticas de Fabricação (BPF) aos produtos hemoterápicos produzidos nos serviços de hemoterapia. Esta norma acompanha o desenvolvimento do Regulamento Técnico de Procedimentos Hemoterápicos, atualizado e publicado periodicamente pelo Ministério da Saúde (atualmente na Portaria GM/MS n ${ }^{\circ}$ 158/2014).

Silva Júnior, Costa e Baccara (2015) comentam que a introdução das BPF, anteriormente pela Agência Estadunidense Food and Drug Administration (FDA) e agora no âmbito dos serviços de hemoterapia brasileiro pela RDC $n^{\circ} 34 / 2014$ da Anvisa, foi importante para o ciclo produtivo, mas a falta de compreensão desse modelo torna os avanços regulatórios fragilizados uma vez que os próprios serviços de hemoterapia não o compreendem. Entretanto, essa é uma discussão imprescindível quando se considera que as práticas adotadas no ciclo do sangue são, em geral, fruto de incorporações técnicas adaptadas da indústria.

\section{Considerações finais}

A prática hemoterápica brasileira tem evoluído não somente em consonância com os demais países e com a comunidade científica internacional, mas também, ao longo desses anos houve uma crescente incorporação da cultura de gestão da qualidade nos processos dos hemocentros. Atualmente é possível avaliar o amadurecimento de alguns conceitos de qualidade, à medida que são discutidos temas como gestão do risco, em que é recomendável a adoção de ações para antecipar a qualquer situação que culmine em risco transfusional.

Nesse sentido, podemos concluir que ao longo dos anos, o papel regulatório e fiscalizador da Vigilância Sanitária tem desenvolvido também um foco mais educativo, servindo de grande alicerce às importantes legislações e à expertise de profissionais nos serviços de hemoterapia que buscam a melhoria contínua dos processos com objetivo de qualidade e de maior segurança.

\section{Referências}

AGÊNCIA NACIONAL DE VIGILÂNCIA SANITÁRIA. Resolução RDC n 151 , de 21 de agosto de 2001. Aprova o Regulamento Técnico sobre Níveis de Complexidade dos Serviços de Hemoterapia, que consta como anexo. Diário 
Oficial [da] República Federativa do Brasil, Poder Executivo, Brasília, DF, 22 ago. 2001. Seção 1, p. 29.

AGÊNCIA NACIONAL DE VIGILÂNCIA SANITÁRIA. Sangue, tecidos, células e órgãos. Brasília, DF, [200-]. Disponível em: <http://portal.anvisa.gov.br/ sangue-tecidos-celulas-e-orgaos $>$. Acesso em: 13 maio 2016.

BARBAN, G. B. Manual técnico para produção e uso do Controle de Qualidade Interno em Testes de Amplificação de Ácidos Nucleicos (CQI-NAT). 2015. 108 f. Dissertação (Mestrado em Hemoterapia e Biotecnologia) - Faculdade de Medicina de Ribeirão Preto, Universidade de São Paulo, Ribeirão Preto, 2015. Disponível em: <http://bdpi.usp.br/item/002714963>. Acesso em: 20 maio 2016.

BRASIL. Constituição da República Federativa do Brasil. Diário Oficial [da] República Federativa do Brasil, Poder Legislativo, Brasília, DF, 5 out. 1988a. Seção 1, p. 1.

BRASIL. Decreto $n^{\circ} 3.990$, de 30 de outubro 2001. Regulamenta o art. 26 da Lei $n^{\circ} 10.205$, de 21 de março de 2001, que dispõe sobre a coleta, processamento, estocagem, distribuição e aplicação do sangue, seus componentes e derivados, estabelece o ordenamento institucional indispensável à execução adequada dessas atividades. Diário Oficial [da] República Federativa do Brasil, Poder Executivo, Brasília, DF, 31 out. 2001 . Seção 1, p. 1.

BRASIL. Lei n ${ }^{\circ}$ 4.701, de 28 de junho de 1965. Dispõe sôbre o exercício da atividade hemoterápica no Brasil e dá outras providências. Coleção de Leis da República Federativa do Brasil, Brasília, DF, v. 6, p. 98, 1 jul 1965.

BRASIL. Lei ${ }^{\circ} 7.649$, de 25 de janeiro de 1988. Estabelece a obrigatoriedade do cadastramento dos doadores de sangue bem como a realização de exames laboratoriais no sangue coletado, visando a prevenir a propagação de doenças, e dá outras providências. Diário Oficial [da] República Federativa do Brasil, Poder Legislativo, Brasília, DF, 27 jan. 1988b. Seção 1, p. 1609.

BRASIL. Lei n 8.080, 19 de setembro de 1990. Dispõe sobre as condições para promoção, proteção e recuperação da saúde, a organização e o funcionamento dos serviços correspondentes e dá outras providências. Diário Ofícial [da] República Federativa do Brasil, Poder Legislativo, Brasília, DF, 20 set. 1990. Seção 1, p. 18055.

BRASIL. Lei $n^{\circ}$ 9.782, de 26 de janeiro de 1999. Define o Sistema Nacional de Vigilância Sanitária, cria a Agência Nacional de Vigilância Sanitária, e dá outras providências. Diário Ofícial [da] República Federativa do Brasil, Poder Legislativo, Brasília, DF, 27 jan. 1999. Seção 1, p. 1. 
BRASIL. Lei ${ }^{\circ} 10.205$, de 21 de março de 2001. Regulamenta o $\S 4^{\circ}$ do art. 199 da Constituição Federal, relativo à coleta, processamento, estocagem, distribuição e aplicação do sangue, seus componentes e derivados, estabelece o ordenamento institucional indispensável à execução adequada dessas atividades, e dá outras providências. Diário Oficial [da] República Federativa do Brasil, Poder Legislativo, Brasília, DF, 22 mar. 2001b. Seção 1, p. 1.

COSTA, E. A. (Org). Vigilância sanitária: temas para debate. Salvador: Edufba, 2009. Disponível em: <http://books.scielo.org/id/6bmrk $>$. Acesso em: 20 maio 2016.

COSTA, E. A.; ROZENFELD, S. Constituição da vigilância sanitária no Brasil. In: ROZENFELD, S. (Org). Fundamentos da vigilância sanitária. Rio de Janeiro: Ed. Fiocruz, 2000. p. 15-40. Disponível em: <http://books.scielo.org/id/ d63fk/04>. Acesso em: 20 maio 2016.

DIAS, H. P. Direitos e obrigações em saúde. Brasília, DF: Anvisa, 2002.

DODD, R. Y.; NOTARI, E. P.; STRAMER, S. L. Current prevalence and incidence of infectious disease markers and estimated window-period risk in the American Red Cross blood donor population. Transfusion, v. 42, n. 8, p. 975979, Aug. 2002.

FUNDAÇÃO HEMOCENTRO DE RIBEIRÃO PRETO. Ribeirão Preto, [200-]. Disponível em: <http://pegasus.fmrp.usp.br/projeto/legislacao.htm>. Acesso em: 9 maio 2016.

FUNDAÇÃO PRÓ-SANGUE. Estudantes. São Paulo, [200-]. Disponível em $<$ http://www.prosangue.sp.gov.br/artigos/estudantes >. Acesso em: 13 maio 2016.

HOGAN, V.; GARGARELLA, G. Revisão do Sistema Nacional de Sangue. Brasília, DF, 1997. Relatório destinado ao Ministério da Saúde.

JUNQUEIRA, P. C.; ROSENBLIT, J.; HAMERSCHLAK, N. História da hemoterapia no Brasil. Revista Brasileira de Hematologia e Hemoterapia, [São Paulo], v. 27, n. 3, p. 201-207, jul./set. 2005. Disponível em: <http://www. scielo.br/scielo.php?script=sci_arttext\&pid=S1516-84842005000300013\&lng =en\&nrm=iso>. Acesso em: 2 maio 2016.

MELO, H. T. Mapeamento do ordenamento jurídico da política nacional de sangue e da regulamentação técnica na área do sangue e derivados. 2015. 102 f. Dissertação (Mestrado em Hemoterapia e Biotecnologia) - Faculdade de Medicina de Ribeirão Preto, Universidade de São Paulo, Ribeirão Preto, 2015. Disponível em: <http://www.teses.usp.br/teses/disponiveis/17/17155/tde22062015-215957/pt-br.php>. Acesso em: 26 maio 2016. 
MURPHY, W. Managing threats rather than risks in blood transfusion: robust design for a complex system. Transfusion, [S.1.], v. 46, n. 11, p. 2011-2013, 2006.

MURPHY, M. F.; STANWORTH, S. J.; YAZER, M. Transfusion practice and safety: current status and possibilities for improvement. Vox Sanguinis, [Oxford], v. 100, n. 1, p. 46-59, 2011.

O’DWYER, G.; REIS, D. C. de S.; SILVA, L. L. G da. Integralidade, uma diretriz do SUS para a vigilância sanitária. Ciência \& Saúde Coletiva, Rio de Janeiro, v. 15, p. 3351-3360, 2010. Suplemento 3.

ORGANIZAÇÃO MUNDIAL DA SAÚDE. Blood transfusion safety: blood system strengthening. Geneva, 2014. Disponível em: <http://www.who.int/ bloodsafety/transfusion_services/blood_systems/en/>. Acesso em: 11 jun. 2014.

PIMENTEL, M. A. A questão do sangue: rumos das políticas públicas de hemoterapia no Brasil e no exterior. 2006. 150 f. Tese (Doutorado em Saúde Coletiva) - Instituto de Medicina Social, Universidade Estadual do Rio de Janeiro, Rio de Janeiro, 2006.

SAMPAIO, D. de A. Cenário político, social e cultural da hemoterapia no Brasil. In: BRASIL. Ministério da Saúde. Técnico em hemoterapia: livro texto. Brasília, DF, 2013. p. 7-18.

SANTOS, L. A. de C.; MORAES, C.; COELHO, V. S. P. Os anos 80: a politização do sangue. Physis: Revista de Saúde Coletiva, Rio de Janeiro, v. 2, n. 1, p. 107149, 1992.

SARAIVA, J. C. P. A história da hemoterapia no Brasil. Revista Brasileira de Hematologia e Hemoterapia, [São Paulo], v. 27, n. 3, p. 153-158, 2005.

SILVA JÚNIOR, J. B.; COSTA, C. da S.; BACCARA, J. P. de A. Regulação de sangue no Brasil: contextualização para o aperfeiçoamento. Revista Panamericana de Salud Pública, Washington, v. 38, n. 4, p. 333-338, 2015. 